\title{
Methylation status of long interspersed element-1 in advanced gastric cancer and its prognostic implication
}

\author{
Young Seok Song • Younghoon Kim • \\ Nam Yun Cho $\cdot$ Han Kwang Yang • \\ Woo Ho Kim • Gyeong Hoon Kang
}

Received: 30 September 2014/ Accepted: 29 December 2014/Published online: 22 January 2015

(C) The International Gastric Cancer Association and The Japanese Gastric Cancer Association 2015

\begin{abstract}
Backgrounds Reportedly, the pyrosequencing methylation assay can produce inconsistent results between paired snap-frozen and formalin-fixed paraffin-embedded archival tissue samples. In this study, we assayed the methylation levels at four individual $\mathrm{CpG}$ sites of $\mathrm{L} 1 \mathrm{using}$ pyrosequencing and found that the methylation levels at individual $\mathrm{CpG}$ sites were different but were closely correlated between paired snap-frozen and formalin-fixed paraffinembedded tissue samples. We aimed to determine whether low methylation status of L1 is associated with gastric cancer patient prognosis.

Methods We analyzed 434 formalin-fixed paraffinembedded tissue samples of advanced gastric cancer for their methylation status at four $\mathrm{CpG}$ sites of $\mathrm{L} 1$ [nucleotide positions 328, 321, 318, and 306 of X58075 (Genbank)] using pyrosequencing, and correlated the L1 methylation level with clinicopathological features.
\end{abstract}

Y. S. Song and Y. Kim contributed equally to this article.

Electronic supplementary material The online version of this article (doi:10.1007/s10120-015-0463-6) contains supplementary material, which is available to authorized users.

Y. S. Song · N. Y. Cho · G. H. Kang

Laboratory of Epigenetics, Cancer Research Institute, Seoul

National University College of Medicine, Seoul, Korea

Y. Kim · W. H. Kim · G. H. Kang ( $\square)$

Department of Pathology, Seoul National University College

of Medicine, 28 Yongon-dong, Chongno-gu, Seoul 110-744,

South Korea

e-mail: ghkang@snu.ac.kr

H. K. Yang

Department of General Surgery, Seoul National University

College of Medicine, Seoul, Korea
Results Older age at onset, males, tumor location at antrum or lower body, intestinal type, and lymphatic or venous invasion were associated with a low average methylation level of $\mathrm{L} 1$ at the two $\mathrm{CpG}$ sites 1 and 4 combined. The average methylation level of $\mathrm{L} 1$ at $\mathrm{CpG}$ sites 1 and 4 combined was significantly lower in microsatellite-stable and EBV-negative gastric cancers than in EBV-positive or microsatellite-unstable gastric cancers. Low methylation status of L1 was independently correlated with shorter overall survival and disease-free survival time. Conclusion Our findings indicate that the discrepancy in the methylation level of L1 between fresh tissue and formalin-fixed paraffin-embedded tissue samples depends on the $\mathrm{CpG}$ sites considered, and that the methylation status of $\mathrm{L} 1$ at $\mathrm{CpG}$ sites 1 and 4 combined could be utilized as a prognostic parameter for advanced gastric cancers.

Keywords Gastric cancer - Long interspersed element-1 . Hypomethylation · Prognosis

\section{Introduction}

DNA methyltransferases methylate cytosines in the context of $\mathrm{CpG}$ dinucleotides, and $75-80 \%$ of $\mathrm{CpG}$ dinucleotides are methylated in normal human cells [1]. CpG sites located in promoter $\mathrm{CpG}$ islands are traditionally thought to be unmethylated, whereas $\mathrm{CpG}$ sites located in repetitive DNA elements are heavily methylated in normal cells. Promoter $\mathrm{CpG}$ island hypermethylation is a common finding in human cancers and is generally associated with an inactive state of the corresponding gene. Although hundreds of genes can undergo hypermethylation in their promoter $\mathrm{CpG}$ island loci in association with cancerization [2], the overall content of methylcytosine generally 
decreases during the malignant transformation from normal cells to cancer cells because of the demethylation of $\mathrm{CpG}$ sites located in repetitive DNA elements, including long interspersed element-1 (LINE-1 or L1) and Alu [3, 4]. Approximately 500,000 copies of L1 are dispersed in the human genome, comprising about $17 \%$ of it, and a fulllength $\mathrm{L} 1$ is about $6 \mathrm{~kb}$ in length [5]. L1 has a high density of CpGs in its initial 460-bp region, where cytosine methylation is maintained with high efficiency [6]. The L1 methylation level has been shown to decrease in gastric epithelial cells with the progression of the lesion along the multistep gastric carcinogenesis, although there are wide variations in L1 methylation levels in gastric cancers (GCs) $[7,8]$. Low L1 methylation status has been demonstrated to be closely associated with shorter survival of the cancer patient, not only for GCs $[7,8]$ but also for colon cancers [9], rectal cancers [10], esophageal squamous cell carcinomas [11], and lung adenocarcinomas [12, 13].

In the literature, there are two studies that have explored the relationships between L1 methylation levels of GC tissue samples and clinical outcomes of cancer patients, and they consistently demonstrated close associations of low L1 methylation status with poor clinical outcomes [7, 8]. These two studies have limitations in that they used formalin-fixed paraffin-embedded (FFPE) archival tissue samples from a small number of GC samples ( $n=193$ and 203). However, a recent study has raised concern over the feasibility of analyzing DNA methylation from DNA obtained from FFPE tissues [14]; Toumier et al. [14] analyzed matched fresh-frozen and FFPE samples from 40 colon adenocarcinomas for their methylation status in L1 using pyrosequencing, and displayed significant differences in L1 methylation level in $28 \%$ of the matched samples. This finding has cast doubt on whether the finding of the previous studies - a close association between low L1 methylation status and poor clinical outcomes of GC patients—is reproducible [7].

In the present study, we collected pairs of matched snapfrozen and FFPE tissue samples $(n=38)$ and analyzed their methylation status in L1 using pyrosequencing. Through this comparison, we found that methylation levels at the four individual $\mathrm{CpG}$ sites assayed in our previous study [7] were different but strongly correlated between paired snap-frozen and FFPE tissue samples. However, the ratio of the methylation level of FFPE tissue to the methylation level of fresh tissue at $\mathrm{CpG}$ sites 1-4 was 1.21:1, 1.05:1, 1.05:1, and 1.19:1, respectively. Then we analyzed a large collection of archival tissue samples of advanced $\mathrm{GC}$ for their methylation status at four $\mathrm{CpG}$ sites of $\mathrm{L} 1$ (CpG sites 1-4) and determined the average methylation levels at two combinations of $\mathrm{CpG}$ sites, 1 and 4 as well as 2 and 3, and we correlated the average L1 methylation level at $\mathrm{CpG}$ sites 1 and 4 combined or at $\mathrm{CpG}$ sites 2 and 3 combined with clinicopathological features, including clinical outcomes.

\section{Materials and methods}

\section{Tissue samples}

The study was approved by the Institutional Review Board of Seoul National University College of Medicine. A consecutive series of advanced GC cases (T2-T4) was retrieved from the surgical files of the Department of Pathology, Seoul National University Hospital, Seoul, Korea. Among the patients who underwent surgery and extended lymph node dissection (D2) for advanced GC between January 2007 and December 2008, only the patients $(n=434)$ who had data for microsatellite instability (MSI), Epstein-Barr virus (EBV), and L1 methylation status were included in this study. Patients who had a history of other primary malignancies within 5 years or received chemotherapy before surgical resection were excluded. The ages of the patients ranged from 23 to 86 years (median, 61 years) and the male to female ratio was $1.95: 1$. The following pathological parameters were evaluated through gross and microscopic examinations: tumor differentiation, histological type (Lauren's classification), lymphatic invasion, perineural invasion, venous invasion, and TNM stage (American Joint Committee on Cancer, 7th edition). For multiple synchronous tumors, data were derived from the high-stage tumor or the larger tumor if the synchronous tumors were of the same stage. Through microscopic examination, areas $\sim 1 \mathrm{~cm}^{2}$ where the tumor cells were the densest and represented the most prevalent histologic type of the individual case were marked and scraped from the tissue glass slide with a knife. In order to determine the suitability of FFPE tissues for methylation analysis, L1 methylation level was assessed for paired snap-frozen and FFPE tissue samples, including 10 normal lymph nodes, 13 gastric mucosal tissues, 5 gastric cancers, 5 colonic cancers, and 5 breast cancers.

Pyrosequencing methylation analysis

The scraped tissue was collected into microtubes containing $50 \mu \mathrm{L}$ of tissue lysis buffer and proteinase $\mathrm{K}$. The tubes were incubated for $24-48 \mathrm{~h}$ at $55{ }^{\circ} \mathrm{C}$ until the tissue-containing buffer fluid turned clear. Proteinase $\mathrm{K}$ was inactivated by incubation at $95{ }^{\circ} \mathrm{C}$ for $10 \mathrm{~min}$. Following centrifugation, the supernatants were transferred into a newly labeled microtube. DNA samples were bisulfitemodified using the EZ DNA methylation kit (Zymo Research, Orange, CA, USA). The modified DNA samples were analyzed for their methylation status in L1 using 
pyrosequencing. In brief, the modified DNA samples were PCR-amplified with the same oligonucleotide primers which were designed by the Issa group for pyrosequencing [15]. These oligonucleotide primers were designed toward a consensus L1 sequence, which allowed the amplification of a representative pool of L1. L1 elements were amplified using $200 \mu \mathrm{M}$ each of the forward primer $5^{\prime}$-TTTTGAGT TAGGTGTGGGATATA- $3^{\prime}$ and the reverse biotinylated primer $5^{\prime}$-AAAATCAAAAAATTCCCTTTC- $3^{\prime}$ in a $50-\mu \mathrm{L}$ reaction volume containing $2.5 \mathrm{ng}$ of bisulfite-treated DNA, $1 \times$ CoralLoad PCR Buffer (contains $1.5 \mathrm{mM}$ $\mathrm{MgCl}_{2}$ ), final $2 \mathrm{mM} \mathrm{MgCl}$, and $1.5 \mathrm{U}$ of HotStarTaq Plus DNA polymerase (Qiagen, Valencia, CA, USA). The PCR thermal amplification profile consisted of an initial denaturation step of $5 \mathrm{~min}$ at $95^{\circ} \mathrm{C}$ followed by 50 cycles of $30 \mathrm{~s}$ at $94{ }^{\circ} \mathrm{C}, 40 \mathrm{~s}$ at $57{ }^{\circ} \mathrm{C}$, and $40 \mathrm{~s}$ at $72{ }^{\circ} \mathrm{C}$. The PCR product was purified using Streptavidin Sepharose High Performance beads (GE Healthcare Bio-Sciences Corp., Uppsala, Sweden) and denatured using denaturation buffer (Qiagen). Next, $0.3 \mu \mathrm{M}$ of the sequencing primer (5'-AGTTAGGTGTGGGATATAGT-3') was annealed to the purified single-stranded PCR product and the pyrosequencing reaction was performed using the PyoMark Q24 platform (Qiagen). The level of methylation at each of the four analyzed $\mathrm{CpG}$ sites [CpG sites 1-4: nucleotide positions 328, 321, 318, and 306, respectively (GenBank accession number X58075)] was expressed as the percentage of methylated cytosines over the sum of methylated and unmethylated cytosines.

\section{MSI determination}

The MSI status was determined using the NCI Bethesda recommended microsatellite markers (BAT-25, BAT-26, D2S123, D5S346, and D17S250). GCs with a high level of MSI (at least $40 \%$ of the markers positive) were considered MSI-high (MSI-H), whereas GCs with a low level of or no MSI ( $<40 \%$ of the markers positive) were considered MSS.

\section{EBV-encoded RNA in situ hybridization}

The presence of EBV in cancer cells was detected by in situ hybridization for EBV-encoded RNA, as described previously [16].

\section{Statistical analysis}

Statistical analyses were performed using SPSS software for windows, version 21.0 (IBM, Armonk, NY, USA). Two-sided $p$ values of less than 0.05 were considered statistically significant. Because data on the L1 methylation level did not follow the normal distribution, mean values across two groups or across three or more groups were compared using the Mann-Whitney $U$ test and KruskalWallis test, respectively. Pearson's correlation test was used to evaluate the correlation between the L1 methylation levels in paired snap-frozen and FFPE tissue samples. The Wilcoxon signed-rank test was used to analyze paired differences. The clinical database was last updated in January 2014. Disease-free survival (DFS) was calculated from the date of resection of advanced GC to the first date of documented recurrence or the date of death from any cause. Overall survival (OS) was measured from the date of operation to the date of death or the last clinical follow-up time. The average follow-up time (from surgery to death or the last follow-up) was 51.7 months (range 0.7-85.0 months). Data from patients who were free from recurrence were censored at the date of the last follow-up visit for DFS. OS and DFS were calculated by the Kaplan-Meier method, and comparisons were made using the log-rank test. Hazard ratios were calculated by the Cox proportional hazards model, and baseline characteristics were adjusted using a backward stepwise model including covariates of prognostic value: age, tumor location within the stomach, lymphatic invasion, venous invasion, perineural invasion, T stage, $\mathrm{N}$ stage, $\mathrm{M}$ stage, and molecular subtype (EBV and MSI status).

\section{Results}

Comparison of L1 methylation level between paired snap-frozen and FFPE tissue samples

Through pyrosequencing, we measured the methylation level at each of the four $\mathrm{CpG}$ sites in both paired snapfrozen and FFPE tissue samples $(n=38)$ and then compared the levels seen in the two types of tissue sample. Although there were strong correlations between the methylation levels seen in the paired snap-frozen tissue samples and the levels seen in the FFPE tissue samples (see Fig. S1 of the Electronic supplementary material, ESM), the two types of samples differed significantly in terms of the methylation level observed at each site (Fig. 1). Compared with snap-frozen tissue samples, FFPE tissue samples showed increased methylation values at all four $\mathrm{CpG}$ sites. However, the fold change (defined as the ratio of the methylation level in FFPE tissue to the methylation level in fresh tissue) varied with the $\mathrm{CpG}$ site considered (1.21-, 1.05-, 1.05-, and 1.19-fold increases were seen at $\mathrm{CpG}$ sites $1-4$, respectively). Because of this variation in the fold change in methylation level, the average methylation level at the four CpG sites in the FFPE tissue samples was not considered to provide a good represention of the average methylation level at the four $\mathrm{CpG}$ sites in the fresh tissue 


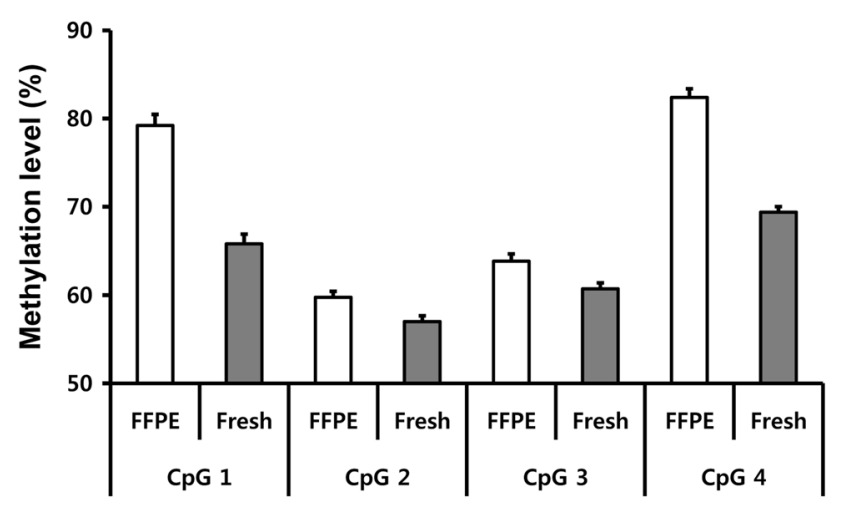

Fig. 1 Comparison between paired snap-frozen and formalin-fixed, paraffin-embedded (FFPE) tissue samples in terms of methylation levels at individual $\mathrm{CpG}$ sites. A paired difference test revealed significant differences between paired snap-frozen and FFPE tissue samples at all four $\mathrm{CpG}$ sites $(P<0.001$ at all four sites $)$

samples. Considering that the fold change seen at $\mathrm{CpG}$ site 2 was similar to that seen at site 3 , and the fold change at $\mathrm{CpG}$ site 1 was similar to that seen at site 4 , we decided to use either the average of the methylation levels at $\mathrm{CpG}$ sites 2 and 3 or the average of the methylation levels at $\mathrm{CpG}$ sites 1 and 4 as representative values of the L1 methylation level in FFPE tissue samples. Regardless of whether the DNA samples were obtained from fresh or FFPE tissue samples, the average methylation level at $\mathrm{CpG}$ sites 2 and 3 combined was closely correlated with the average methylation level at $\mathrm{CpG}$ sites 1 and 4 combined (see Fig. S2 of the ESM).

Relationship between L1 methylation level and clinicopathological features

The average methylation level at $\mathrm{CpG}$ sites 1 and 4 combined or at $\mathrm{CpG}$ sites 2 and 3 combined showed close associations with age, gender, tumor location within the stomach, histologic type (Lauren's classification), lymphatic emboli, venous invasion, and molecular subtype (Table 1). The average methylation level of $\mathrm{L} 1$ at $\mathrm{CpG}$ sites 1 and 4 combined or at CpG sites 2 and 3 combined was higher in younger patients than in older patients at onset, in female than in male patients, in GCs involving the high body than in GCs not involving the high body, in diffuse type or mixed type than in intestinal type, in EBVpositive or MSI-H than in MSS/non-EBV type, in GCs with no lymphatic emboli than in GCs with lymphatic emboli, and in GCs with no venous invasion than in GCs with venous invasion. The average methylation level of L1 at $\mathrm{CpG}$ sites 1 and 4 combined or at $\mathrm{CpG}$ sites 2 and 3 combined tended to be higher in GCs with perineural invasion than in GCs without perineural invasion ( $P=0.076$ and $P=0.055$, respectively). The average methylation level of $\mathrm{L} 1$ at $\mathrm{CpG}$ sites 1 and 4 combined or at $\mathrm{CpG}$ sites 2 and 3 combined tended to be lower in GCs with nodal metastasis than in GCs without nodal metastasis ( $P=0.0325$ and $P=0.055$, respectively). The average methylation level of $\mathrm{L} 1$ at $\mathrm{CpG}$ sites 1 and 4 combined or at $\mathrm{CpG}$ sites 2 and 3 combined did not correlate with tumor depth or distant metastasis.

\section{L1 methylation level and patient survival}

Patient survival was followed-up in 432 patients since two patients were lost during the follow-up. By performing univariate analysis with serial cutoff values from the lowest to the highest methylation level of $\mathrm{L} 1$ at $\mathrm{CpG}$ sites 2 and 3 combined or $\mathrm{CpG}$ sites 1 and 4 combined, we found that setting the cutoff value at $59.3 \%$ for $\mathrm{CpG}$ sites 2 and 3 or $72.1 \%$ for $\mathrm{CpG}$ sites 1 and 4 generated the greatest prognostic value in relation to both overall survival (OS) and disease-free survival (DFS). A low methylation status of $\mathrm{L} 1$ at $\mathrm{CpG}$ sites 2 and $3(<59.3 \%)$ or $\mathrm{CpG}$ sites 1 and 4 $(<72.1 \%)$ was closely associated with OS time and DFS time (Fig. 2a-d). Through the Kaplan-Meier log-rank test, we found that older age at onset, tumor location in the high body, higher $\mathrm{T}$ stage, higher $\mathrm{N}$ stage, distant metastasis, venous invasion, lymphatic invasion, and perineural invasion were closely associated with a shorter OS and DFS time (Table 2; Table S1 of the ESM). Molecular subtype (EBV-positive, MSI-H, and MSS/non-EBV) was closely associated with DFS but not with OS. When both methylation statuses (at $\mathrm{CpG}$ sites 2 and 3 and at $\mathrm{CpG}$ sites 1 and 4) and other covariates that are of prognostic value according to the Kaplan-Meier log-rank test were incorporated into the multivariate models, low methylation status of $\mathrm{L} 1$ at $\mathrm{CpG}$ sites 1 and 4 was found to correlate independently with $\mathrm{OS} \quad(\mathrm{HR}=2.269 ; 95 \% \quad \mathrm{CI}$, 1.591-3.236) (Table 3) and DFS (HR $=2.468 ; 95 \% \mathrm{CI}$, 1.750-3.481) (Table S2 of the ESM), but low methylation status of $\mathrm{L} 1$ at $\mathrm{CpG}$ sites 2 and 3 did not.

\section{Discussion}

In line with a previous study [14], our study has demonstrated a significant difference in L1 methylation level (i.e., the average of the methylation levels at four $\mathrm{CpG}$ sites) between paired fresh-frozen and FFPE tissue samples, although when the methylation level at each $\mathrm{CpG}$ site was considered in turn, the levels seen in paired fresh-frozen and FFPE tissue samples were observed to be closely correlated. All four $\mathrm{CpG}$ sites showed higher methylation levels in the FFPE tissue samples than in the paired fresh-frozen tissue samples, and the fold increases noted at $\mathrm{CpG}$ sites 1 and 4 were observed to be similar, as were the fold increases seen at $\mathrm{CpG}$ sites 2 and 3 . Thus, the average of the methylation levels at $\mathrm{CpG}$ sites 2 
Table 1 Relationships between average L1 methylation level and clinicopathological parameters of gastric cancer patients

\begin{tabular}{|c|c|c|c|c|c|c|}
\hline \multirow[t]{2}{*}{ Characteristic } & \multirow[t]{2}{*}{ Variable } & \multirow[t]{2}{*}{ No. of cases } & \multicolumn{4}{|l|}{ Average methylation level (\%) } \\
\hline & & & CpG sites 1 and 4 combined & $P$ value & $\mathrm{CpG}$ sites 2 and 3 combined & $P$ value \\
\hline \multirow[t]{2}{*}{ Age } & $<61$ year & 210 & 81.2 & 0.040 & 66.0 & 0.021 \\
\hline & $\geq 61$ year & 224 & 79.0 & & 64.1 & \\
\hline \multirow[t]{2}{*}{ Sex } & Male & 287 & 79.1 & 0.017 & 64.3 & 0.011 \\
\hline & Female & 147 & 81.9 & & 66.4 & \\
\hline \multirow[t]{2}{*}{ Tumor subsite } & Not involving high body & 311 & 79.2 & 0.014 & 64.3 & 0.002 \\
\hline & Involving high body & 123 & 82.2 & & 66.8 & \\
\hline \multirow[t]{4}{*}{ Stage } & I & 53 & 81.7 & 0.432 & 65.9 & 0.446 \\
\hline & II & 148 & 80.6 & & 65.6 & \\
\hline & III & 184 & 79.1 & & 65.0 & \\
\hline & IV & 49 & 80.3 & & 63.9 & \\
\hline \multirow[t]{3}{*}{ T stage } & $\mathrm{T} 2$ & 99 & 79.5 & 0.387 & 64.6 & 0.747 \\
\hline & $\mathrm{T} 3$ & 167 & 79.5 & & 64.9 & \\
\hline & $\mathrm{T} 4$ & 168 & 81.0 & & 65.4 & \\
\hline \multirow[t]{4}{*}{$\mathrm{N}$ stage } & N0 & 131 & 82.4 & 0.032 & 66.6 & 0.051 \\
\hline & N1 & 84 & 79.8 & & 64.9 & \\
\hline & $\mathrm{N} 2$ & 81 & 78.1 & & 64.0 & \\
\hline & N3 & 138 & 79.2 & & 64.1 & \\
\hline \multirow[t]{2}{*}{ M stage } & M0 & 385 & 80.0 & 0.866 & 65.2 & 0.329 \\
\hline & M1 & 49 & 80.3 & & 63.9 & \\
\hline \multirow{4}{*}{$\begin{array}{l}\text { Lauren } \\
\text { classification }\end{array}$} & Intestinal & 163 & 75.9 & $<0.001$ & 62.0 & $<0.001$ \\
\hline & Diffuse & 206 & 83.3 & & 67.3 & \\
\hline & Mixed & 58 & 80.7 & & 65.6 & \\
\hline & Unclassified & 7 & 76.0 & & 64.1 & \\
\hline \multirow[t]{2}{*}{ Venous invasion } & Absent & 325 & 81.5 & $<0.001$ & 66.0 & $<0.001$ \\
\hline & Present & 109 & 75.9 & & 62.0 & \\
\hline \multirow[t]{2}{*}{ Lymphatic emboli } & Absent & 163 & 81.6 & 0.028 & 66.3 & 0.014 \\
\hline & Present & 271 & 79.1 & & 64.3 & \\
\hline \multirow[t]{2}{*}{ Perineural invasion } & Absent & 196 & 79.0 & 0.076 & 64.2 & 0.055 \\
\hline & Present & 238 & 81.0 & & 65.7 & \\
\hline \multirow[t]{3}{*}{ Molecular subtype } & EBV-positive & 33 & 86.1 & $<0.001$ & 70.2 & $<0.001$ \\
\hline & MSI-H & 52 & 83.1 & & 67.9 & \\
\hline & MSS/non-EBV & 347 & 79.1 & & 64.1 & \\
\hline
\end{tabular}

and 3 and the average of the methylation levels at $\mathrm{CpG}$ sites 1 and 4 were calculated for the FFPE tissue samples and were considered to represent the methylation levels of $\mathrm{L} 1$ at $\mathrm{CpG}$ sites 2 and 3 and $\mathrm{CpG}$ sites 1 and 4 in fresh tissue samples, respectively. The present study demonstrated that a low methylation status of $\mathrm{L} 1$ at $\mathrm{CpG}$ sites 1 and 4 or $\mathrm{CpG}$ sites 2 and 3 was associated with older age at onset, males, tumor location at lower body or antrum, intestinal type, lymphatic or venous invasion, and MSS/non-EBV molecular subtype. Multivariate analysis revealed that a low methylation status of L1 at CpG sites 1 and 4 was an independent prognostic parameter heralding a poor prognosis in patients with advanced GC.
Because we did not conduct laser capture microdissection in the the present study, concern may well be raised over whether infiltrating immune and stromal cells may influence the analysis of L1 methylation level in GC tumor samples [4, 17]. After we estimated the ratio of tumor cells to non-neoplastic cells in tumor areas marked for manual dissection, we grouped the GC cases into two subsets according to tumor purity $[<50 \%(n=211)$ and $\geq 50 \%$ $(n=221)$ ] and then evaluated the prognostic potential of low methylation status of $\mathrm{L} 1 \mathrm{CpG}$ sites 1 and 4 in each subset. Low methylation status of L1 CpG sites 1 and 4 was not prognostic in a subset with tumor purity $<50 \%$ (Fig. S3 of the ESM) but was prognostic in subsets of 
Fig. 2a-d Kaplan-Meier survival analysis with the logrank test. Low methylation status $(<72.1 \%)$ of $\mathrm{L} 1$ at $\mathrm{CpG}$ sites 1 and 4 was closely associated with shorter overall survival (a) and disease-free survival time (b). Low methylation status $(<59.3 \%)$ of $\mathrm{L} 1$ at $\mathrm{CpG}$ sites 2 and 3 was closely associated with shorter overall survival (c) and diseasefree survival time (d)
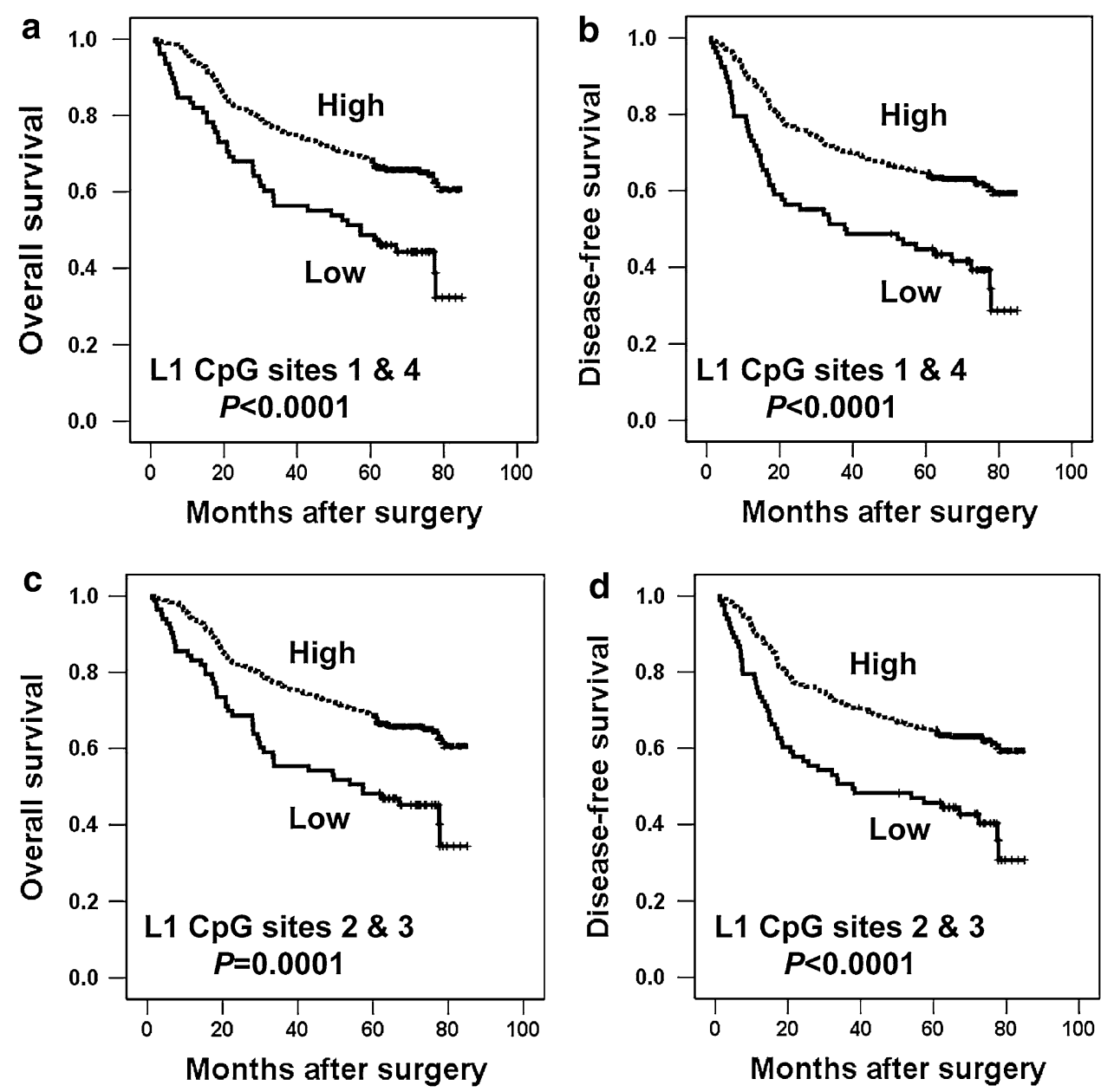

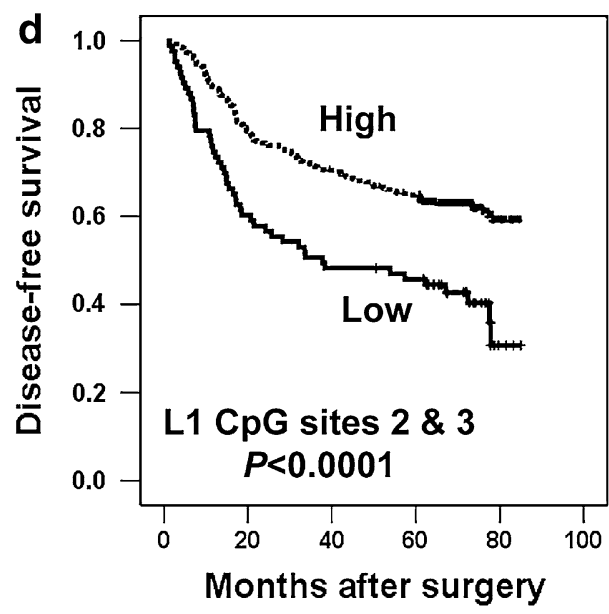

tumor purity $\geq 50 \%$ (Fig. S4 of the ESM). In multivariate analyses of GCs of tumor purity $\geq 50 \%(n=221)$, low methylation status of $\mathrm{L} 1$ at $\mathrm{CpG}$ sites 1 and 4 was an independent prognostic factor for OS and DFS (Tables S3 and S4 of the ESM). These findings suggest that infiltrating immune and stromal cells may perturb the prognostic significance of L1 methylation status in GCs of low tumor purity. Laser capture microdissection is necessary to enrich the proportion of tumor cells in order to elucidate whether low methylation status of L1 is a prognostic factor for GCs with low tumor purity.

In a recent integrative genomic study of GCs [18], GCs were classified into EBV-positive, MSI-H, and MSS/nonEBV, and further subclassifed into intestinal-, diffuse-, and mixed-type tumors. That study, which used the Illumina 450k Human Methylation assay, demonstrated that EBV-positive GCs have the highest degree of genomewide hypermethylation but a minimal degree of genomewide demethylation, whereas MSI-H GCs have both genome-wide hypermethylation and demethylation. However, the high degree of genome-wide demethylation seen in MSI-H GCs in that study contrasts with the high methylation level of L1 seen in the present study. This apparent discrepancy is related to the fact that the Illumina 450k Human Methylation array does not cover $\mathrm{CpG}$ sites located within L1 [19]. Further study is required to check whether MSI-H GCs show extensive demethylation at $\mathrm{CpG}$ sites located outside $\mathrm{CpG}$ island loci and repetitive DNA elements but maintain a high methylation state at CpG sites located within repetitive DNA elements. In the present study, EBV-positive GCs showed a higher methylation level of L1 than the other molecular subtypes did. Because EBV-positive GCs tend to be associated with high immune cell infiltration, it is unclear whether a high level of methylation in L1 was related to high immune cell infiltration. However, when we compared EBVpositive GCs of low tumor purity $(<50 \%)$ with those of high tumor purity $(\geq 50 \%)$ in terms of the methylation level of $\mathrm{L} 1$ at $\mathrm{CpG}$ sites 2 and 3 or at $\mathrm{CpG}$ sites 1 and 4, we did not observe any difference in methylation level. Furthermore, when the comparison was restricted to GCs of tumor purity $\geq 70 \%$, EBV-positive GCs showed a higher methylation level of $\mathrm{L} 1$ at $\mathrm{CpG}$ sites 2 and 3 or at CpG sites 1 and 4 than MSI-H GCs or MSS/EBV-negative 
Table 2 Univariate analysis of overall survival (OS) in 432 patients with advanced gastric cancer

\begin{tabular}{|c|c|c|c|c|}
\hline Characteristic & Variable & Number of cases & 3- and 5-year OS (\%) & $P$ value \\
\hline \multirow[t]{2}{*}{ Age } & $<61$ year & 210 & 75.2 and 70.5 & 0.0323 \\
\hline & $\geq 61$ year & 222 & 69.4 and 59.4 & \\
\hline \multirow[t]{2}{*}{ Tumor subsite } & Not involving high body & 310 & 77.4 and 71.9 & $<0.0001$ \\
\hline & Involving high body & 122 & 59.0 and 46.7 & \\
\hline \multirow[t]{4}{*}{ Stage } & I & 52 & 94.2 and 84.6 & $<0.0001$ \\
\hline & II & 148 & 89.9 and 83.8 & \\
\hline & III & 183 & 65.0 and 56.8 & \\
\hline & IV & 49 & 22.5 and 16.3 & \\
\hline \multirow[t]{3}{*}{ T stage } & $\mathrm{T} 2$ & 98 & 89.8 and 81.6 & $<0.0001$ \\
\hline & $\mathrm{T} 3$ & 167 & 86.2 and 78.4 & \\
\hline & $\mathrm{T} 4$ & 167 & 47.9 and 41.3 & \\
\hline \multirow[t]{4}{*}{$\mathrm{N}$ stage } & No & 130 & 90.8 and 84.6 & $<0.0001$ \\
\hline & N1 & 84 & 82.1 and 75.0 & \\
\hline & $\mathrm{N} 2$ & 81 & 76.5 and 65.4 & \\
\hline & N3 & 137 & 46.0 and 39.4 & \\
\hline \multirow[t]{2}{*}{ M stage } & M0 & 383 & 78.6 and 71.0 & $<0.0001$ \\
\hline & M1 & 49 & 22.5 and 16.3 & \\
\hline \multirow[t]{4}{*}{ Lauren classification } & Intestinal & 163 & 76.7 and 67.5 & 0.2694 \\
\hline & Diffuse & 205 & 66.7 and 61.3 & \\
\hline & Mixed & 58 & 81.0 and 70.7 & \\
\hline & Unclassified & 7 & 57.1 and 57.1 & \\
\hline \multirow[t]{2}{*}{ Venous invasion } & Absent & 325 & 78.8 and 70.5 & $<0.0001$ \\
\hline & Present & 107 & 52.3 and 47.7 & \\
\hline \multirow[t]{2}{*}{ Lymphatic emboli } & Absent & 163 & 88.3 and 82.2 & $<0.0001$ \\
\hline & Present & 270 & 62.5 and 54.3 & \\
\hline \multirow[t]{2}{*}{ Perineural invasion } & Absent & 195 & 80.5 and 71.8 & 0.0009 \\
\hline & Present & 237 & 65.4 and 59.1 & \\
\hline \multirow[t]{3}{*}{ Molecular subtype } & EBV-positive & 33 & 75.8 and 66.7 & 0.1391 \\
\hline & MSI-H & 51 & 82.4 and 76.4 & \\
\hline & MSS/non-EBV & 347 & 70.2 and 63.0 & \\
\hline \multirow[t]{2}{*}{ Methylation level of $\mathrm{L} 1$ at $\mathrm{CpG}$ sites 2 and 3} & Low $(<59.3 \%)$ & 83 & 55.4 and 48.2 & 0.0001 \\
\hline & High $(\geq 59.3 \%)$ & 349 & 76.2 and 68.8 & \\
\hline \multirow[t]{2}{*}{ Methylation level of $\mathrm{L} 1$ at $\mathrm{CpG}$ sites 1 and 4} & Low $(<72.1 \%)$ & 78 & 56.4 and 48.7 & $<0.0001$ \\
\hline & High $(\geq 72.1 \%)$ & 354 & 75.7 and 68.4 & \\
\hline
\end{tabular}

GCs did. To clarify whether tumor cells of EBV-positive GCs have a high level of L1 methylation, a laser capture microdissection-based study is necessary.

Because L1 methylation status was associated with EBV-positive or MSI-H GCs, we could question whether the more favorable outcome in cases with high levels of L1 methylation is simply a reflection of the known better outcomes of these types of GC. When we restricted survival analysis to MSS/non-EBV GCs, tumoral L1 hypomethylation was still found to be an independent prognostic parameter heralding poor prognosis in terms of both OS and DFS. Low methylation status of $\mathrm{L} 1$ at $\mathrm{CpG}$ sites 1 and 4 correlated independently with OS
$(\mathrm{HR}=2.350 ; 95 \% \mathrm{CI}, 1.604-3.442)$ and DFS $(\mathrm{HR}=$ 2.393; $95 \%$ CI, 1.663-3.445).

In our study to compare the L1 methylation levels at four individual $\mathrm{CpG}$ sites between paired snap-frozen and FFPE tissue samples, the methylation levels in the four individual $\mathrm{CpG}$ sites were found to be significantly higher in FFPE tissue samples than in paired snap-frozen tissue samples, although methylation levels in the paired snapfrozen and FFPE tissue samples were closely correlated. The reason for the discrepancy in L1 methylation levels between the paired tissue samples may be the incomplete bisulfite conversion of FFPE tissue DNA, and the remaining unmethylated cytosines may contribute to the 
Table 3 Multivariate analysis of overall survival

\begin{tabular}{|c|c|c|c|}
\hline Characteristic & Variable & Adjusted HR (95\% CI) & $P$ value \\
\hline \multirow[t]{2}{*}{ L1 methylation ( $\mathrm{CpG}$ sites 1 and 4$)$} & Low $(<59.3 \%)$ & $2.269(1.591-3.236)$ & $<0.001$ \\
\hline & High $(\geq 59.3 \%)$ & Reference & \\
\hline \multirow[t]{2}{*}{ L1 methylation (CpG sites 2 and 3) } & Low $(<72.1 \%)$ & $1.076(0.552-2.100)$ & 0.829 \\
\hline & High $(\geq 72.1 \%)$ & Reference & \\
\hline \multirow[t]{2}{*}{ Age } & Low ( $<61$ year) & Reference & \\
\hline & High ( $\geq 61$ year $)$ & $1.834(1.332-2.527)$ & $<0.001$ \\
\hline \multirow[t]{2}{*}{ Tumor subsite } & Not involving high body & Reference & \\
\hline & Involving high body & $1.936(1.409-2.660)$ & $<0.001$ \\
\hline \multirow[t]{3}{*}{$\mathrm{T}$ stage $<0.001$} & $\mathrm{~T} 2$ & Reference & \\
\hline & $\mathrm{T} 3$ & $0.717(0.423-1.213)$ & 0.215 \\
\hline & $\mathrm{T} 4$ & $2.072(1.249-3.436)$ & 0.005 \\
\hline \multirow[t]{4}{*}{$\mathrm{N}$ stage $<0.001$} & NO & Reference & \\
\hline & N1 & $1.329(0.749-2.358)$ & 0.331 \\
\hline & $\mathrm{N} 2$ & $1.279(0.725-2.254)$ & 0.395 \\
\hline & N3 & $2.715(1.629-4.527)$ & $<0.001$ \\
\hline \multirow[t]{2}{*}{ M stage } & M0 & Reference & \\
\hline & M1 & $3.405(2.303-5.034)$ & $<0.001$ \\
\hline \multirow[t]{2}{*}{ Lymphatic emboli } & Absent & Reference & \\
\hline & Present & $1.424(0.953-2.127)$ & 0.085 \\
\hline \multirow[t]{2}{*}{ Venous invasion } & Absent & Reference & \\
\hline & Present & $1.100(0.786-1.540)$ & 0.578 \\
\hline \multirow[t]{2}{*}{ Perineural invasion } & Absent & Reference & \\
\hline & Present & $1.011(0.687-1.487)$ & 0.955 \\
\hline
\end{tabular}

increased methylation values in FFPE tissue samples compared with paired snap-frozen tissue samples. To identify whether the overestimation is related to the methylation assessment technique used, we assessed L1 methylation using the MethyLight technology in paired snap-frozen and FFPE tissue samples $(n=38)$ and found that L1 methylation levels were significantly higher in FFPE tissue samples than in paired snap-frozen tissue samples (data not shown), which indicates that overestimation of methylation levels in FFPE tissue samples may be observed ubiquitously in methylation assessment techniques that use both bisulfite conversion and polymerase chain reaction.

Although the present study has demonstrated a close association between low methylation status of L1 and worse clinical outcomes of GC patients, the molecular biological mechanism that links low L1 methylation status to aggressive GC behavior is unclear. Three aspects can be considered. First, genomic demethylation, represented by low L1 methylation status, might lead to chromosomal instability [20, 21]. Genomic demethylation might lead to overexpression of satellite DNA sequences which might induce chromosomal instability [22]. Chromosomal instability is accompanied by copy number gain or amplification of proto-oncogenes, the generation of fusion genes, and copy number loss of tumor suppressor genes, which might contribute to aggressive tumor cell behavior. Second, decreased methylation of L1 sequences might lead to aberrant overexpression of proto-oncogenes or decreased expression of genes harboring L1 sequences in their intronic sequences [23-25]. Third, because a small proportion of L1 sequences are capable of retrotransposition, which can cause genome-wide mutations, demethylationinduced activation of L1 sequences might lead to genomic instability. Nevertheless, the mechanism that connects low L1 methylation status to aggressive tumor cell behavior remains unclear and needs to be fully explored.

In conclusion, the findings of our present study support those of previous studies: that low L1 methylation status is significantly and independently associated with poor prognosis of GC patients. Further study using fresh tissue samples of GC is necessary to confirm the strong association between tumoral L1 hypomethylation and poor prognosis of GC patients.

Acknowledgments This study was supported by a grant from the Basic Science Research Program through the National Research Foundation of Korea (NRF) funded by the Ministry of Education (2013R1A1A2059080), a grant from the Korean Health Technology R\&D Project, Ministry of Health \& Welfare (HI13C1804), a grant from the Priority Research Centers Program through the National 
Research Foundation of Korea (NRF) funded by MEST (20090093820), an NRF grant funded by the Ministry of Science, ICT and Future Planning (MSIP) (2011-0030049), and a grant of the Korea Health Technology R\&D Project through the Korea Health Industry Development Institute (KHIDI) funded by the Ministry of Health \& Welfare, Republic of Korea (HI14C1277).

Conflict of interest The authors declare that they have no conflict of interest.

\section{References}

1. Cooper DN, Krawczak M. Cytosine methylation and the fate of CpG dinucleotides in vertebrate genomes. Hum Genet. 1989;83(2):181-8.

2. The Cancer Genome Atlas Network. Comprehensive molecular characterization of human colon and rectal cancer. Nature. 2012;487(7407):330-7. doi:10.1038/nature11252.

3. Weisenberger DJ, Campan M, Long TI, Kim M, Woods C, Fiala $\mathrm{E}$, et al. Analysis of repetitive element DNA methylation by MethyLight. Nucleic Acids Res. 2005;33(21):6823-36. doi:10. 1093/nar/gki987.

4. Chalitchagorn K, Shuangshoti S, Hourpai N, Kongruttanachok N, Tangkijvanich $\mathrm{P}$, Thong-ngam $\mathrm{D}$, et al. Distinctive pattern of LINE-1 methylation level in normal tissues and the association with carcinogenesis. Oncogene. 2004;23(54):8841-6. doi:10. 1038/sj.onc. 1208137.

5. Lander ES, Linton LM, Birren B, Nusbaum C, Zody MC, Baldwin $\mathrm{J}$, et al. Initial sequencing and analysis of the human genome. Nature. 2001;409(6822):860-921. doi:10.1038/35057062.

6. Woodcock DM, Lawler CB, Linsenmeyer ME, Doherty JP, Warren WD. Asymmetric methylation in the hypermethylated CpG promoter region of the human L1 retrotransposon. J Biol Chem. 1997;272(12):7810-6.

7. Bae JM, Shin SH, Kwon HJ, Park SY, Kook MC, Kim YW, et al. ALU and LINE-1 hypomethylations in multistep gastric carcinogenesis and their prognostic implications. Int $\mathrm{J}$ Cancer. 2012;131(6):1323-31. doi:10.1002/ijc.27369.

8. Shigaki H, Baba Y, Watanabe M, Murata A, Iwagami S, Miyake $\mathrm{K}$, et al. LINE-1 hypomethylation in gastric cancer, detected by bisulfite pyrosequencing, is associated with poor prognosis. Gastric Cancer. 2013;16(4):480-7. doi:10.1007/s10120-0120209-7.

9. Ogino S, Nosho K, Kirkner GJ, Kawasaki T, Chan AT, Schernhammer ES, et al. A cohort study of tumoral LINE-1 hypomethylation and prognosis in colon cancer. J Natl Cancer Inst. 2008;100(23):1734-8. doi:10.1093/jnci/djn359.

10. Benard A, van de Velde CJ, Lessard L, Putter H, Takeshima L, Kuppen PJ, et al. Epigenetic status of LINE-1 predicts clinical outcome in early-stage rectal cancer. $\mathrm{Br} \mathrm{J}$ Cancer. 2013;109(12):3073-83. doi:10.1038/bjc.2013.654.

11. Iwagami S, Baba $Y$, Watanabe M, Shigaki H, Miyake K, Ishimoto $\mathrm{T}$, et al. LINE-1 hypomethylation is associated with a poor prognosis among patients with curatively resected esophageal squamous cell carcinoma. Ann Surg. 2013;257(3):449-55. doi:10.1097/SLA.0b013e31826d8602.
12. Ikeda K, Shiraishi K, Eguchi A, Shibata H, Yoshimoto K, Mori T, et al. Long interspersed nucleotide element 1 hypomethylation is associated with poor prognosis of lung adenocarcinoma. Ann Thorac Surg. 2013;96(5):1790-4. doi:10.1016/j.athoracsur.2013. 06.035 .

13. Baba Y, Murata A, Watanabe M, Baba H. Clinical implications of the LINE-1 methylation levels in patients with gastrointestinal cancer. Surg Today. 2014;44(10):1807-16. doi:10.1007/s00595013-0763-6.

14. Tournier B, Chapusot C, Courcet E, Martin L, Lepage C, Faivre $\mathrm{J}$, et al. Why do results conflict regarding the prognostic value of the methylation status in colon cancers? The role of the preservation method. BMC Cancer. 2012;12:12. doi:10.1186/14712407-12-12.

15. Tellez CS, Shen L, Estecio MR, Jelinek J, Gershenwald JE, Issa JP. CpG island methylation profiling in human melanoma cell lines. Melanoma Res. 2009;19(3):146-55.

16. Kang GH, Lee S, Cho NY, Gandamihardja T, Long TI, Weisenberger DJ, et al. DNA methylation profiles of gastric carcinoma characterized by quantitative DNA methylation analysis. Lab Invest. 2008;88(2):161-70. doi:10.1038/labinvest.3700707.

17. Yoshihara K, Shahmoradgoli M, Martinez E, Vegesna R, Kim H, Torres-Garcia W, et al. Inferring tumour purity and stromal and immune cell admixture from expression data. Nat Commun. 2013;4:2612. doi:10.1038/ncomms3612.

18. Wang K, Yuen ST, Xu J, Lee SP, Yan HH, Shi ST, et al. Wholegenome sequencing and comprehensive molecular profiling identify new driver mutations in gastric cancer. Nat Genet. 2014;46(6):573-82. doi:10.1038/ng.2983.

19. Bibikova M, Barnes B, Tsan C, Ho V, Klotzle B, Le JM, et al. High density DNA methylation array with single $\mathrm{CpG}$ site resolution. Genomics. 2011;98(4):288-95. doi:10.1016/j.ygeno.2011. 07.007 .

20. Lengauer C, Kinzler KW, Vogelstein B. DNA methylation and genetic instability in colorectal cancer cells. Proc Natl Acad Sci USA. 1997;94(6):2545-50.

21. Karpf AR, Matsui S. Genetic disruption of cytosine DNA methyltransferase enzymes induces chromosomal instability in human cancer cells. Cancer Res. 2005;65(19):8635-9. doi:10. 1158/0008-5472.CAN-05-1961.

22. Zhu Q, Pao GM, Huynh AM, Suh H, Tonnu N, Nederlof PM, et al. BRCA1 tumour suppression occurs via heterochromatinmediated silencing. Nature. 2011;477(7363):179-84. doi:10. 1038/nature 10371.

23. Wolff EM, Byun HM, Han HF, Sharma S, Nichols PW, Siegmund $\mathrm{KD}$, et al. Hypomethylation of a LINE-1 promoter activates an alternate transcript of the MET oncogene in bladders with cancer. PLoS Genet. 2010;6(4):e1000917. doi:10.1371/journal. pgen.1000917.

24. Aporntewan C, Phokaew C, Piriyapongsa J, Ngamphiw C, Ittiwut $\mathrm{C}$, Tongsima $\mathrm{S}$, et al. Hypomethylation of intragenic LINE-1 represses transcription in cancer cells through AGO2. PLoS One. 2011;6(3):e17934. doi:10.1371/journal.pone.0017934.

25. Hur K, Cejas P, Feliu J, Moreno-Rubio J, Burgos E, Boland CR, et al. Hypomethylation of long interspersed nuclear element-1 (LINE-1) leads to activation of proto-oncogenes in human colorectal cancer metastasis. Gut. 2014;63(4):635-46. doi:10.1136/ gutjnl-2012-304219. 